Public Abstract

First Name:Harith

Middle Name:Hasoon

Last Name:Al-Moameri

Adviser's First Name:Galen

Adviser's Last Name:Suppes

Co-Adviser's First Name:

Co-Adviser's Last Name:

Graduation Term:SP 2017

Department:Chemical Engineering

Degree:PhD

\title{
Title:SIMULATION AIDED ANALYSIS AND EXPERIMENTAL STUDY OF POLYURETHANE POLYMERIZATION REACTION AND FOAMING PROCESS
}

From an engineering perspective, simulation of urethane polymerization reactions is a great opportunity in the polymer area based on a) the current $\$ 20$ billion market expected to grow to over $\$ 50$ billion in the next couple of decades and $b$ ) the stage of the technology where formulation development is substantially an art but the capability exists to convert it to a science.

The simulation project presented in this paper is based on fundamental approaches of mass transfer, heat transfer, and reaction kinetics to calculate the rate of changes of concentrations, foam height, bubble radius, and rate of mass transfer as an ordinary differential equation solved by ODE45 MatLab function. The simulation is based on the simultaneous solution of typically $25-80$ ordinary differential equations that describe elementary reactions, energy balances, and mass transfer. Laboratory polymerization experiments were performed to evaluate the accuracy of the simulations, including setting up experimental systems and measurement of temperature, height, and viscosity profiles of the urethane systems. Experimental results show good agreement with the simulation results of reaction temperature, foam height, cell radius, and resin viscosity.

While the initial intent of the simulation was to use an understanding of the fundamental processes to produce a useful and practical tool that could reduce the need of experimental investigation to develop new formulations, the reverse result of using experimental results to provide insight into the fundamental processes is proving to be as much the norm of the R\&D process as the latter. 